\title{
Compatibility of Ethiopia's Import Regulation of Genetically Modified Organisms (GMOs) with WTO Rules
}

\author{
Gizachew Girma, Zemenu Yesigat \\ College of Law, Dire Dawa University, Dire Dawa, Ethiopia
}

Email address:

gizachew2587@yahoo.com (G. Girma), zyisraelia@gmail.com (Z. Yesigat)

\section{To cite this article:}

Gizachew Girma, Zemenu Yesigat. Compatibility of Ethiopia's Import Regulation of Genetically Modified Organisms (GMOs) with WTO Rules. Humanities and Social Sciences. Vol. 3, No. 6, 2015, pp. 286-292. doi: 10.11648/j.hss.20150306.11

\begin{abstract}
Ethiopia- a party to CPB- needs to benefit from the advantages of modern biotechnology, by managing the possible risks occasioned as a result of the application of the technology on human and animal health, biological diversity and the environment. In an attempt to implement the obligations under the protocol, the country promulgated Biosafety proclamation and Directives which regulate among other things import of GMOs. As Ethiopia is on the way to join the WTO, compatibility of the legal system with WTO rules that would otherwise affect international trade has paramount importance either to facilitate the accession or to prevent future trade disputes before the WTO dispute settlement body. And hence, the purpose of this paper is to explore the regulatory framework of import regulation of GMOs in Ethiopia and to assess its compatibility with WTO rules- namely SPS, TBT and GATT agreements.
\end{abstract}

Keywords: Import Regulation, Ethiopia, WTO, SPS, TBT, GATT, GMO

\section{Introduction}

Genetic engineering allows scientists to reorder the basic building blocks of life to create new varieties of living organisms. The creators of these genetically modified organisms (here in after GMOs) emphasize the potential of genetic engineering to benefit society by, for example, increasing crop yields or improving food quality. However, there is increasing concern that GMOs could pose a threat to human health and the environment. People have also expressing their concern about the ethical and social implications of genetic engineering. [Matthew, 1999]

Especially their threat to the environment has led many countries, to call for regulating the transaction of all products containing GMOs. Accordingly, the Protocol, known as the Cartagena Protocol on Biosafety to the Convention on Biological Diversity, was adopted in Montreal on 29 January 2000 and entered in to force on 2003 [here in after CPB].

Many states, partially to fulfill their obligation they assumed under the protocol and partially due to the need to protect the adverse effects of GMOs started to adopt domestic regulatory framework to GMOs. These domestic regulation schemes, however, are threatened by the international trading rules enforced by the World Trade Organization.
Until recently, although Biosecurity does not appear in any policy document in Ethiopia, there are some attempts to adopt specific regulatory provisions in scattered sectoral laws to realize the demands of Biosecurity. These Various laws have empowered several agencies to undertake inspections of food quality, issue procedures and standards against risks of plant and animal diseases and thereby enhance human health and environmental sustainability. The problem, however, is these sectoral legislations are not comprehensive and are not harmonized with respect to the mandates of the implementing institutions so as to effectively sustain Biosecurity.

GMOs are regulated in Ethiopia under the Biosafety proclamation No. 655/2009 (here in after proclamation), which provides a general framework from which other regulations and directives to be enacted for its enforcement. The objective of this Proclamation as provided in article 4 is "to protect human and animal health, biological diversity, the environment, local communities and the country at large by preventing or managing down to levels of insignificance the adverse effects of modified organisms." The cumulative reading of article 2(2) and article 3 suggest that the Proclamation applies to any transaction whether intended for release into the environment, for use as a pharmaceutical for humans or animals, or for food, feed or processing.

The proclamation establishes procedures of prior 
notification to and authorization for any transaction of products containing GMOs. It contains the basic provisions that are required in order to implement the obligations of the $\mathrm{CPB}$. Articles 5,6 , and 8 , require a party seeking to release a GMO into Ethiopia to submit notification undertake Risk Assessment and obtain prior informed agreement. In addition, Articles 7 of the proclamation also provides for the identification, labeling and packaging of GMOs or their products. Post-authorization monitoring and inspections are also regulated in article $19 \& 20$ of the proclamation. In article 21 criminal sanctions are imposed on offenders who contravene the mandatory obligations of the proclamation such as those on notification, risk assessment and compliance with standards. 12

Environment Protection Authority, established by Proclamation No. 295/2002 [here in after EPA] is designated to be the responsible authority for its implementation. EPA is also authorized to issue directives necessary for the implementation of the proclamation. Accordingly, the authority issued six directives in 2011 and put in place. The Directives are intended to determine the contents of applications for undertaking transactions involving modified organisms; risk assessment parameters for modified organisms; procedures of a risk management strategy for dealing with accidents involving modified organisms; requirements for the transport of modified organisms; storing and processing of modified organisms; responses to accidental releases of modified organisms.

Generally, the nature of the regulatory frame work of the import regulation of GMOs can be classified in to two main types of measures- approval procedure to engage in any transaction of GMOs and mandatory labeling of GMOs and their products.

\section{Assessing Compatibility of the Import Regulation with WTO Agreements}

Biotechnology-related concerns are increasingly cropping up in trade discussions, both at the World Trade Organization (WTO) and in other forums. Trade problems arise when countries have different regulations regarding the testing and approval procedures necessary to place GMOs and their products on the market, or when they disagree about labeling and identification requirements. [SPS Training Module, 2009] Thus, assessing the compatibility of the import regulation regime is of much important to know the possible challenges we face in applying these measures being the member of WTO. Since Several WTO agreements that establish different degree of strictness and flexibility to be met in applying trade restrictive measures could apply to the import regulation of GMOs, including SPS, TBT and the GATT; determining which agreement would apply is practically important step to assess the legality of the measure under WTO.

The SPS Agreement applies if the measures were aimed at the protection from food safety risks or from damage caused by pests. Any such measures should either be based on international standards or on a risk assessment. The TBT Agreement applies to product requirements that are mandatory (technical regulations) as well as voluntary (standards) and to conformity assessment procedures not covered by the SPS Agreement. Also of relevance is the General Agreement on Tariffs and Trade (GATT), which deals with trade in goods and contains several provisions; for example those referring to non-discrimination and quantitative restrictions, that are relevant to the trade in GMOs. Furthermore, Article XX sets out a number or exceptions, allowing Members to take measures which would otherwise violate GATT rules to, inter alia, protect public morals, human, animal or plant life or health and to conserve exhaustible natural resources (Article XX(a), (b) and (g)).

In assessing the legality of the import regulation under WTO agreements, first we need have to make a threshold determination of the scope of the protection the regulation is seeking, what risks it is designed to protect against and the form and nature of the measure. If the measure sought to protect the legitimate interests and take the form enumerated under Annex A/1 of the SPS agreement it would fall squarely within the definition of a SPS measure under the SPS Agreement. Furthermore, if it sought to protect the legitimate objective and falls within the definition of technical regulation, standard or conformity procedures its legality is assessed in light of the TBT agreement.

\subsection{Purpose of the Import Regulation}

When we look at the objective of the import regulation we can see that it serve to protect human and animal health, biological diversity, the environment, local communities and the country at large. The objective seen facially is much broader scope than legitimate interests provided under SPS agreement and thus address also the TBT agreement. Thus, it can be said that the measures falls under both TBT and SPS agreement, in fact it is a legitimate right to do so as the Panel in EC - GMOs (Biotech) Case recognized the possibility and right of a member to impose a single measure, which falls at the same time, within the scope of both SPS and TBT agreement. In such a case the panel holds that the consolidated law qualifies as a technical regulation within the meaning of Annex 1(1) of the TBT Agreement. Nevertheless, Article 1.5 of the TBT agreement makes clear that to the extent the requirement at issue qualifies as an SPS measure, the provisions of the TBT Agreement would "not apply", even though the requirement at issue is contained in a law which meets the definition of a technical regulation. Therefore, to the extent the import regulation is applied for purposes which are identified in annex A (1), it is governed by the SPS Agreement; to the extent the legislation is applied for other purposes, it falls within the scope of the TBT Agreement. Since the approval procedures are conducted for a number of purposes (namely, to avoid various adverse effects), it is better to view the import regulation as incorporating an SPS measure as well as a non-SPS measure.

Based on the aforementioned analysis it is better to look 
how the objectives which facially seems out of the coverage of the SPS agreement- namely protection of the environment, biological diversity, economic risk- are partially governed by SPS agreement. It is clear from the preamble of the proclamation that as part of the purpose of protecting the "environment" it addresses the protection of human and animal health. Panel in EC - GMOs (Biotech) note that in accordance with Annex A(1)(a) and (b) of the SPS Agreement, the SPS Agreement covers measures applied to protect animal and human life or health from certain risks. Thus, to the extent the proclamation and the directives are applied to protect animals and humans as part of their purpose of protecting the environment, they are not a priori excluded from the scope of application of the SPS Agreement. In the Environment Policy of Ethiopia, there are features pertinent to the enhancement of human health and the protection of animals and plants from pests and diseases that strengthen this line of argument. [Daniele, et al., 2007]Therefore, measures aimed at protecting animals and humans as part of their purpose of protecting the environment are SPS measure by their purpose.

According to article 2(9) of the proclamation, the import regulation is also designed to avert risks on economic condition of local communities. The Panel in EC - GMOs (Biotech), held that the word "other damage" in Annex A (1) (d) of SPS agreement is broad, so as to cover economic damage arising from pests. Therefore, as long as the economic damage is arisen from pests, SPS agreement is applicable. Moreover, the panel holds that a measure applied to prevent damage to "biodiversity" may qualify as a measure applied to protect animal or plant life or health from the kind of risks referred to in Annex A (1)(a) and (b). And hence those measure qualifies as such can be covered by the SPS agreement.

After considering the purposes which fall under SPS agreement now we are going to determine those risks the import regulation seeks to avert which afoul on TBT agreement. As we have said above, those measures covered under SPS agreement are out of the scope of TBT agreement. In fact, however, that does not mean that member states can't impose a measure in accordance with TBT agreement. Therefore, those measures which are out of the scope of SPS agreement can be examined under TBT agreement. Among the objective of the import regulation, Protecting the environment and biodiversity are the legitimate objectives to be covered under the TBT agreement. Since measures applied to protect animals, plants and humans as part of their purpose of protecting the environment and biodiversity are covered by the SPS agreement they are out of the scope of TBT. However, protection of the environment and biodiversity is broad by far, from protection of the flora and fauna as the term environment also includes lithosphere and atmosphere. In the same fashion, protection of biodiversity despite its probability to qualify as a measure intended to protect human, animal and plant life and health, is most likely out of the SPS agreement. Accordingly, measures which are aimed at protecting the environment and biodiversity which are not covered by SPS agreement afoul under the TBT agreement legitimate objectives.

In addition to the aforementioned objectives the import regulation also seeks to avert socio economic and cultural conditions of local communities and the country as a whole. As we have seen above, economic damage arising from pests is covered under SPS agreement, and hence out of the scope of TBT agreement. Besides, measures aimed at protecting social and cultural conditions of the community are not legitimate interests covered under TBT agreement. Consequently, measures other than aiming at protecting economic damage arising from pests and social and cultural conditions of the community will be examined in light of the TBT agreement.

\subsection{Assessing Compliance with SPS Agreement}

Assessing whether the Import regulation complies with the SPS Agreement involves determining whether the Import regulation is indeed a SPS measure in its form and nature so that affect international trade, and if so, whether it is based on risk assessment on sound scientific evidence or it conforms with international standard or not so that it is applied only to the extent necessary to protect the legitimate objectives. In doing so it is useful first to outline what the TBT Agreement requires, in the actual text of the agreement and in the jurisprudence created by the WTO Appellate Body.

I. Is the Import Regulation SPS Measure in its Form and nature?

As discussed above, the import regulation has two kinds of measures, namely the approval procedure and mandatory labeling. To say that these measures are SPS they should coincide with the form and nature of the alleged measure as provided under SPS agreement. With regard to the form criteria Annex A (1) of SPS agreement indicates that SPS measures "include" all "laws, decrees [and] regulations". In EC - GMOs (Biotech) case the panel outlined that the reference to l'aws, decrees [and] regulations" should not be taken to prescribe a particular legal form. Rather, SPS measures may in principle take many different legal forms.Accordingly, since the import regulation is based on binding laws- proclamation and directives- it meets the form test.

\section{A. Approval Procedures}

Regarding the nature of SPS measures, the Panel in EC GMOs (Biotech) stated that 'the second paragraph of Annex A (1) refers to a variety of "requirements and procedures" which are quite different in nature. Among the "procedures" specified in Annex A (1) are "testing, inspecting, certification and approval procedures." Annex A (1) does not define the term "approval procedures". However, Annex $\mathrm{C}$ to the SPS Agreement, which is entitled "Control, Inspection and Approval Procedures", contains a footnote which clarifies that "[c]ontrol, inspection and approval procedures include, inter alia, procedures for sampling, testing and certification."The requirement to have an Advanced Informed Agreement to import GMOs and the procedures to be followed in order to obtain it, meets the nature of SPS measure as certification and approval procedure stated under 
Annex A (1).

B. Identification and Labeling Requirements

The proclamation requires identification and labeling to indicate the presence of a GMO in cases where EPA has determined that the release of the relevant GMO into the environment is safe for both human health and the environment. A requirement to indicate the presence of a GMO in such cases may not at first glance appear to be a measure that would fall within the scope of the SPS Agreement. That is because labeling is usually meant to serve as consumers' information which has no direct contact with protection of health or life of living organisms. Therefore, we think we should examine whether the labeling requirement in the directive is linked to the purpose of protecting human health and the environment and hence is a measure applied for one of the purposes identified in Annex A(1) of SPS agreement.

Article 15 of the proclamation provide the instances whereby EPA may revise its decision on Advanced Informed Agreement when it later discovered information that indicates the existence of significant risk from the modified organism after it authorized transaction to be made. In addition, if the conditions contained in an Advanced Informed Agreement are not strictly complied with, EPA may take a measure for the immediate cessation of the transaction, including the destruction of the modified organism. Moreover, the consent holder is also duty bound to notify EPA if he discover other possible significant risk after receiving the advance informed agreement. In such a case the only means to trace the modified organisms from conventional products is to look in to the information contained on the package of the products. In the same scenario, the Panel in EC - GMOs (Biotech) ruled that explicit identification of the presence in a product of a GMO may be presumed to result in consent holders and competent authorities being better informed, or informed more promptly, than they otherwise would be of unanticipated risks of a GMO to human health and the environment, allowing them to determine whether additional measures are necessary to protect human health and the environment. Thus labeling here is serving as precautionary measure when there is scientific uncertainty to protect the legitimate objectives under the SPS agreement.

If we say that labeling requirement is rationally related to the purpose of protecting human health and the environment, now it is better to see whether it conform with the form and nature of Annex A(1). Panel in EC - GMOs (Biotech) note that "Annex A (1) to the SPS Agreement specifies that SPS measures include, inter alia, packaging and labeling requirements directly related to food safety." As it is indicated by the term "inter alia" in Annex A (1), the requirements specifically mentioned are not necessarily intended to exclude similar requirements. Hence, while recognizing that labeling requirements imposed on food safety grounds may be more common, we consider that labeling requirements imposed for the purpose of protecting plant, animal or human health from the risks covered in Annex A (1) (a) and (c), or for the purpose of preventing or limiting other damage from the risk covered in Annex A (1) (d), would likewise be subject to the disciplines of the SPS Agreement." Therefore, it can be said that the identification and labeling requirement as provided under article 7 of the proclamation qualified as SPS measure.

II. Whether the Import Regulation Affect International Trade

Article 1.1 of the SPS Agreement provides, among other things, that the SPS Agreement äpplies to all [SPS] measures which may, directly or indirectly, affect international trade." Thus, for SPS measure to be subject to the disciplines of the SPS Agreement, it must be capable of affecting international trade. Accordingly, we now turn to consider, as an additional and separate matter, whether the import regulation may affect international trade. The Panel, in EC - GMOs (Biotech) note that the approval procedures may themselves have a direct or indirect effect on international trade; because their completion takes time, or because they impose information and documentation requirements on applicants. Thus there is no reason that the WTO dispute settlement body to rule Ethiopian approval procedure doesn't affect international trade if the case appears before it. Besides, Article 7(1) of the proclamation requires GMOs package to be labeled in both Amharic and English language. This is beyond contestation imposed burden on whether the consent holder or the manufacturer to incur an extraordinary expense due to multiple reasons. To name one, it may be argued that labeling in Amharic needs additional time and extraordinary expense to have Amharic speaker expert. Therefore, the import regulation affects international trade beyond reasonable doubt.

III. Whether the Import Regulation is Applied Only to the Extent Necessary to Protect Legitimate Objectives

After we determine that the import regulation is in part qualified as SPS measure now we are going to assess its compliance with SPS agreement. Article 2.2 of the agreement obliges members to ensure that their SPS measures are applied only to the extent necessary to protect the legitimate objectives. For that matter it obliges them to base their measure on risk assessments based on scientific evidence or to take measures based on international standards. The proclamation refers to the Cartagena Protocol on Biosafety which seems relevant in this case. The problem, however, is the pane in EC - GMOs (Biotech) case ruled that the protocol has no relevance to interpret the SPS agreement. Therefore, Ethiopia will never benefit from the protocol as an international standard despite the fact that more than 150 states are members to it. However, the proclamation in many instances indicates the applicability of acceptable international agreements. Especially article 3(2) provides that '[a]ny treaty on the regulation of [GMOs] ... that has been declared to have no adverse effect shall be applied.' According to Article 14(1) and 12(g) of the Proclamation, national clearing house contains relevant international agreements and in turn these agreements are taken in to consideration when the EPA renders decision. Thus it can be 
argued that in taking any measure Ethiopia will take relevant international standards and guidelines qualified so by the agreement. If it would happen it can be said that the import regulation is prima facie, in compliance with the SPS agreement until it is rebutted that it conflicts with the necessity test. Despite these facts the import regulation can also be justified under Article 5(7) which allows provisional measures to be taken when there is scientific uncertainty on the basis of available pertinent information, including from the relevant international organizations as well as from SPS measures applied by other Members. Unless and otherwise the specific measures taken creates unnecessary obstacle to international trade as it has been happened in the EC GMOs (Biotech) case, the mere approval procedure and labeling requirement will never be considered to violate SPS agreement.

\subsection{Assessing Compliance with the TBT Agreement}

We have already said that the import regulation is meant to protect the legitimate objectives that are covered by the TBT agreement so that TBT agreement will be applicable to technical regulations which are not covered by SPS agreement. Assessing whether the Import regulation complies with the TBT Agreement involves determining whether the Import regulation is indeed a technical measure, and if so, whether it uses an international standard for its basis or not and finally whether the import regulation meets the national treatment requirement. In doing so it is useful first to outline what the TBT Agreement requires, in the actual text of the agreement and in the jurisprudence created by the WTO Appellate Body.

I. Is the Import Regulation a Technical Measure?

The Appellate Body in EC-Sardines outlined three criteria that a document must meet to be considered a technical regulation. First, the measure must apply to an identifiable product or group of products. Second, the document must lay down one or more characteristics of the product. Third, compliance with the product characteristics must be mandatory. The proclamation and all the six Directives meet all of these requirements. They apply to GMOs exclusively and Art 2(1) Proclamation and common art 2(2) of all the EPA Directives define a GMO clearly as "any biological entity which has been artificially synthesized, or in which the genetic material or the expression of any of its traits has been changed by the introduction of any foreign gene or any other chemical whether taken from another organism, from a fossil organism or artificially synthesized." This definition lays down characteristics of the products it sought to regulate. Article 5 of the Directive issued to determine the contents of applications for undertaking transactions involving modified organisms includes detailed requirements for information submitted for notification and risk assessment purposes. These information requirements indicate the type of information which the EPA will consider in approving the release of a GMO. Finally, compliance with both approval procedure and labeling requirement are mandatory. That is, as per Article 5(1) \& 7(1) of the Proclamation neither any transaction on GMOs may be done without going through an approval process nor any transaction on GMOs be made without labeling.

II. Does the Import Regulation Use an International Standard 'as a Basis'?

Unlike Article 5.2 of the SPS, which requires Members to base risk assessments on scientific evidence, Article 2.2 of the TBT only requires a Member to consider "available scientific ...information" among other considerations. In addition, Article 2.4 of the TBT Agreement requires Members to use international standards or the relevant parts of them, where available, "as a basis for their technical regulations." Initially, TBT Agreement appears more stringent than the SPS Agreement in that it mandates, where international standards exist, that they must be followed. However, the TBT Agreement is vaguer than the SPS Agreement in defining what constitutes international standard.

Indeed, the strictest rule regarding international standards is that the international body that produces the standard must be open to all Members of the WTO. The most obvious candidate for an international standard in the case of Ethiopian Import regulation is the one set forth in the $\mathrm{CPB}$ since the proclamation and all the Directives explicitly referred to it. Moreover, article 14 of the proclamation makes it clear that the protocol should be taken in to consideration when the EPA makes any decisions. As mentioned above, the Panel in EC - GMOs (Biotech) hold that the protocol doesn't qualified as international standard for SPS measures since many WTO members do not ratified it. Like the EC - GMOs (Biotech) case the panel in Sardines argued that only standards that have been adopted by consensus are relevant for the purposes of Article 2.4 of the TBT Agreement. The Appellate Body, however, disagreed and held that a standard only need to meet the definition of a standard set forth in Annex 1.2 of the TBT Agreement. This seems because of the fact that, unlike the SPS Agreement, international standards are not well defined in the TBT Agreement. And hence, probably the protocol may be relevant international standard to TBT measures.

The problem, however, is there is some slight difference between the protocol and the proclamation. That is The Proclamation applies to any transaction whether intended for release into the environment, for use as a pharmaceutical for humans or animals, or for food, feed or processing, that seems broader than that of the CPB, which exempts pharmaceuticals and GMOs intended for food, feed or processing or for contained use from the Advance Informed Agreement procedure set forth by the CPB. The Appellate Body in EC- Sardines interpreted the term "basis" as used in Article 2.4 of the TBT Agreement to mean that, at a minimum, the international standard cannot be a "basis" for a measure if the two contradict each other. The truth, however, is in our case the difference doesn't amount to contradiction. That is article 5 of CPB doesn't totally make pharmaceuticals outside the applicability of the protocol. Rather what it makes is the same as what Article 3(2) of proclamation states- 
recognize the application of those international treaties on pharmaceuticals used for humans. Moreover, the same provision of the protocol recognize the right of a Party to subject all living modified organisms to risk assessment prior to the making of decisions on import. In other cases there is no clear deviation from the protocol. Therefore, we can say that there is no contradiction between the two so that Ethiopia enjoys a rebuttable presumption that the import regulation does not create an unnecessary obstacle to international trade.

III. The National Treatment Provision -- Are GMOs and Conventional Products "Like"?

If a Member can show it has used an international standard as a basis for its technical measure, Article 2.5 of the TBT Agreement provides that there is a presumption that the measure does not create an unnecessary obstacle to international trade. This presumption, however, does not apply to Article 2.1 of the TBT Agreement, which requires that no less favorable treatment be afforded to "like" products. If two products are determined to be like, then they cannot be regulated differently. While likeness under Article 2.1 of the TBT Agreement has not been interpreted in the WTO, the Appellate Body in EC- Asbestos look at likeness under Article III (4) of the GATT. Even though a determination of likeness has different implications under the GATT and TBT Agreements, the reasoning used to assess likeness under both agreements would be similar.[ Aaron, 2004] Under Article III (4) of the GATT, the Appellate Body determined that for regulatory measures, like products are those products that could be determined to be in a competitive relationship with each other. In determining whether products are in a competitive relationship with each other, the Appellate Body in EC- Asbestos made it clear that consumer tastes and habits, especially in regards to products which are considered to be hazardous to health or the environment, can be taken into account and may prove dispositive in finding that two products are not directly competitive and therefore not "like." While the Asbestos case dealt with asbestos fibers, a product that is clearly hazardous to human health, it may not be necessarily relevant that there is uncertainty regarding the risks GMOs pose to human health and the environment so long as consumers perceive that there are risks. If consumers perceive that GMOs pose risks to human health and the environment, regardless of whether this is scientifically demonstrated, and this affects the competitive relationship between GMOs and their conventional counterparts, then, under Asbestos reasoning they are not like products therefore may be regulated differently. In the country like Ethiopia whereby there is strong religious and ethical values inherent to most of the societies, there will be no doubt that the two are going to be considered as different products.

\subsection{Compliance with GATT Art. XX}

The GATT, SPS and the TBT Agreements have concurrent application, with the TBT and SPS Agreements imposing obligations that are different from and additional to the
GATT. Therefore, even if a measure is found to be lawful under the TBT and SPS Agreements, it may still violate the GATT. Moreover, the import regulation has also included protection of social and cultural conditions that cannot be justified, neither in terms of scientific assessment of risk nor by the TBT agreement. Therefore, it is necessary to discuss briefly, how the import regulation is also compatible with the GATT. The most appropriate instrument for review of legality under WTO may be Article III (4) of the GATT that forbids Members from giving less favorable treatment to products which are considered the same or directly competitive. As shown above, the Appellate Body decision in Asbestos would support a finding that GMOs and their conventional counterparts are not like products and therefore may be regulated differently.

Still, if the import regulation is deemed to be inconsistent with Article III (4) of the GATT, it could still be justified either under Article XX (a) or (b) of the GATT, exemptions for public morals or protecting human health. The exemption for public morals seems to be designed for countries with high religious and cultural values such as Ethiopia where by eating many animals and plants are said to be unethical and immoral in most of the society either in their cultural or religious dogmas. Furthermore, the import regulation may also be justifiable under subparagraph (b) of Article XX of the GATT, which allows members to violate Article III of the GATT if it is "necessary to protect human ... health." The Appellate Body in EC- Asbestos determined that a Member, in justifying a measure under Article XX (b) of the GATT, may rely on scientific sources which represent a divergent opinion. In addition, the Appellate Body also stated that a panel need not rely on the preponderant weight of the evidence to deem an action is justifiable under Article XX (b) of the GATT. This indicates that an action could potentially be based on a minority scientific opinion, which advocated for precaution due to a lack of clear evidence of safety. The Appellate Body also made it clear that the term "necessary" means there is no less trade--restrictive measure available. In both cases it seems too easy to justify i.e. at least there are some scientists who vehemently argue that GMOs are dangerous that leads to the conclusion of CPB and there would be no less trade restrictive measure than to go through approval procedure and labeling requirement. Totally, in no case the import regulation would be incompatible with GATT obligation.

\section{Conclusion}

Even though there are elements of the import regulation of GMOs deal with protecting human and animal health either as part of their purpose of protecting the environment and biodiversity or targeting principally on themselves, it is at also equally concerned with the protection of the environment and biodiversity in there broader definition and seeks to mitigate risks to the socio-economic and cultural conditions of the local communities and the country at large. This fact allows it, to operate within the scope of the SPS Agreement which is lex specialis of the TBT Agreement and 
also to be considered under the more general TBT Agreement for those measures afoul outside of the SPS agreement. Moreover, there are also instances whereby we are obliged to assess its compatibility with the GATT provisions. When we examine the compatibility of the import regulation with three of the WTO agreement we will reach to a conclusion that the mere approval procedure and labeling requirement doesn't amounts to violation of any of the agreements unless the specific measures that will be taken in the future creates unnecessary obstacle to international trade as it has been happened in EC- GMOs (Biotech) case. Thus the import regulation is compatible to all the SPS, TBT and GATT.

\section{References}

[1] Aaron A. Ostrovsky, 2004, the EC Regulations for GMO and the Current WTO Dispute -Human Health or Environmental Measures? 15 COLO. J. INT'L ENVTL. L. \& POL'Y 209.

[2] Daniele Manzella\& Jessica Vapnek, 2007, Development of an analytical tool to assess Biosecurity legislation, FAO LEGISLATIVE STUDY 96, Rome.

[3] Matthew Stilwell And Brennan Van Dyke, 1999, An Activist's Handbook On Genetically Modified Organisms And The WTO, Second Edition.
[4] EFDR Biosafety proclamation No. 655/2009, Federal Negarit Gazeta (Page 4962- 4975), 15th Year No. 63, Addis Ababa, 2009.

[5] Cartagena Protocol on Biosafety to the Convention on Biological Diversity, Feb. 23, 2000.

[6] WTO Legal Texts Result of the Uruguay Round Final Text, eleg-gen-5. doc; Annex 1A of the Marrakech Agreement Multilateral Agreements on Trade in Goods, General Agreement on Tariffs and Trade 1994 ("GATT1994").

[7] WTO Legal Texts Result of the Uruguay Round Final Text, eleg-sps-14.doc; Annex 1A of the Marrakech Agreement, Multilateral Agreements on Trade in Goods, agreement on the Application of Sanitary and Phytosanitary Measures.

[8] WTO Legal Texts Result of the Uruguay Round Final Text, eleg-tbt-16. doc; Annex 1A of the Marrakech Agreement, Multilateral Agreements on Trade in Goods, Agreement on Technical Barriers to Trade.

[9] WTO, Report of the Appellate Body, European Communities - Measures Affecting Asbestos and Asbestos Containing Products, WT/DS135/AB/R (Mar. 2001).

[10] WTO, Report of the Appellate Body, European Communities - Trade Description of Sardines, WT/DS231/AB/R (Sept. 2002)

[11] WTO, Report of the Panel, European Communities Measures Affecting the Approval and Marketing of Biotech Products, WT/DS291/R, (Sept. 2002). 